\title{
Real-World Efficacy and Safety of Dulaglutide in Korean Patients with Type 2 Diabetes Mellitus: A Retrospective Study in a Tertiary Referral Center
}

\author{
Jee Hee Yoon, A Ram Hong*, Wonsuk Choi, Ji Yong Park, Hee Kyung Kim, and Ho-Cheol Kang \\ Department of Internal Medicine, Chonnam National University Medical School, Gwangju, Korea
}

This study was conducted to evaluate the efficacy and safety of once-weekly dulaglutide therapy as add-on to oral antidiabetic drugs (OADs) and basal insulin in Korean patients with type 2 diabetes mellitus (T2DM) in real-world clinical practice. We retrospectively reviewed the medical records of 112 patients who received dulaglutide in a tertiary referral center. The primary efficacy endpoint was a change in glycated hemoglobin (HbA1c) between baseline and 6 months. The secondary endpoints were the percentage of patients achieving $\mathrm{HbA} 1 \mathrm{c}<7.0 \%$ or $\leq 6.5 \%$ and the change of body weight at 6 months. At baseline, the mean $\mathrm{HbA1c}$ was $8.7 \%$ (8.8\% in the OAD combination and $8.5 \%$ in the basal insulin combination group). The mean adjusted HbA1c at 6 months decreased by $-1.13 \%$ in all patients $(\mathrm{p}<0.001)$, and by -1.36 and $-0.74 \%$ in the $\mathrm{OAD}$ combination and basal insulin combination group, respectively. A significant reduction of $-2.9 \mathrm{~kg}$ in body weight was observed in all patients at 6 months $(\mathrm{p}<0.001)$. Approximately $34.8 \%$ and $23.2 \%$ of patients achieved $\mathrm{HbA} 1 \mathrm{c}<7.0 \%$ and $\leq 6.5 \%$, respectively. Higher baseline $\mathrm{HbA} 1 \mathrm{c}$ and no previous insulin therapy were associated with positive responses to dulaglutide on multivariate analysis. Mild gastrointestinal issues $(23.2 \%)$ were the most frequently observed adverse events. Dulaglutide is an effective and durable treatment option as $\mathrm{OAD}$ and basal insulin combination therapy in Korean patients with T2DM.

Key Words: Dulaglutide; Diabetes Mellitus, Type 2; Blood Glucose

This is an Open Access article distributed under the terms of the Creative Commons Attribution Non-Commercial License (http://creativecommons.org/licenses/by-nc/4.0) which permits unrestricted non-commercial use, distribution, and reproduction in any medium, provided the original work is properly cited.

\section{Article History}

Received May 18, 2021

Revised July 2, 2021

Accepted July 3, 2021

\section{Corresponding Author:}

A Ram Hong

Department of Internal Medicine,

Chonnam National University Medical

School, 160 Baekseo-ro, Dong-gu,

Gwangju 61469, Korea

Tel: +82-61-379-7635

Fax: +82-61-379-7628

E-mail: wanilove23@nate.com

\section{INTRODUCTION}

Type 2 diabetes mellitus (T2DM) is emerging as a prevalent disease worldwide and affects $14.4 \%$ of adults aged 30 or older in Korea. ${ }^{1}$ A wide range of glucose-lowering agents has been developed to achieve glycemic target goals in T2DM, which is a chronic, progressive, metabolic disorder. The American Diabetes Association and the European Association for the Study of Diabetes recommend metformin as the first-line therapy for T2DM. ${ }^{2,3}$ When additional antidiabetic therapies are required to achieve the glycemic target, an individualized, patient-based approach, with due consideration to the presence of atherosclerotic cardiovascular disease and chronic kidney disease, body weight, hypoglycemia, and cost-effectiveness, is recommended. The glucagon-like peptide-1 (GLP-1) receptor agonist (RA) is preferred as the second-line therapeutic agent in patients who need adjuvant antidiabetic therapy. Moreover, GLP-1 RAs are preferred injectable therapies for insulin in patients with inadequate glycemic control with oral antidiabetic drugs (OADs).

GLP-1 is an incretin hormone, which increases glucose load-based insulin secretion and decreases glucagon secretion, and thereby slows gastric emptying and reduces appetite. ${ }^{4}$ The GLP-1 RAs have demonstrated glucose-lowering efficacy with a low risk of hypoglycemia as well as marked body weight reduction in several randomized controlled trials (RCTs) ${ }^{5-7}$ In addition, treatment with GLP-1 RA has showed a significant reduction of major cardiovascular disease risk and mortality, and improved renal outcomes. $^{8}$

Dulaglutide is a long-acting human GLP-1 RA that has 
been approved for the treatment of T2DM, and is administered weekly. Since its introduction, the usage of dulaglutide has continuously increased in Korea. The initiation of dulaglutide therapy can be considered in various clinical settings; however, given concerns associated with insurance coverage, dulaglutide is generally used in combination therapy with OAD or basal insulin. Several recent real-world studies have shown consistent glucose-lowering efficacy with body weight reduction in patients with T2DM treated with dulaglutide when compared with the results from previous RCTs. ${ }^{9,10}$ Similar findings from Korean patients with T2DM were reported in two studies that evaluated the glycemic efficacy of dulaglutide for 6 months. ${ }^{11,12}$ However, little is known about the differences in glucoselowering efficacy of dulaglutide according to the background glucose-lowering regimen.

Therefore, this study aimed to evaluate the efficacy and safety of dulaglutide as OAD and basal insulin combinations in a real-world clinical setting in Korean patients with T2DM.

\section{MATERIALS AND METHODS}

\section{Study population}

We retrospectively reviewed the medical records of patients with T2DM who started dulaglutide therapy at Chonnam National University Hwasun Hospital between January 2017 and August 2019. This study included patients with T2DM who received dulaglutide for more than 6 months. We excluded patients who had been previously treated with other types of GLP-1 RA, those who had self-reported low adherence, and received high-dose steroid therapy and chemotherapy during dulaglutide therapy for the analysis. We further excluded the patients who experienced significant changes in treatment regimens, such as the addition of insulin or change in OAD class at the initiation of dulaglutide or during the treatment. A total of 112 patients were included in the final analysis. The patients were divided into two groups according to the background glucose-lowering therapy: the OAD combination group (i.e., dulaglutide in combination with OADs) and the basal insulin combination group (i.e., dulaglutide in combination with basal insulin). The OAD combination group was further subdivided into two groups based on the history of insulin therapy prior to the initiation of dulaglutide. Meanwhile, the basal insulin combination group was further subdivided into two groups by the history of bolus insulin therapy prior to the initiation of dulaglutide therapy.

This study was conducted in accordance with the Declaration of Helsinki and was reviewed by the Institutional Review board of Chonnam National University Hwasun Hospital (IRB No.: CNUHH-2019-085). The need for informed consent was waived due to the retrospective nature of the study.

\section{Efficacy and safety assessment}

For the evaluation of clinical characteristics, we collected data on age, sex, body weight, body mass index (BMI), duration of diabetes, total daily insulin dose, and comorbidities including hypertension, dyslipidemia, and cardiovascular diseases. The HbA1c measurements were conducted at baseline, and repeated after 3 months ( \pm 4 weeks) and 6 months ( \pm 4 weeks) following dulaglutide initiation. We further collected data on the levels of fasting plasma glucose (FPG), total cholesterol, triglyceride, high-density lipoprotein-cholesterol, low-density lipoprotein-cholesterol, liver enzymes, serum creatinine, and estimated glomerular filtration rate (eGFR).

The primary efficacy endpoint was a change in HbA1c between baseline and 6 months. The secondary efficacy endpoints were the percentage of patients who achieved a glycemic target of $\mathrm{HbA} 1 \mathrm{c}<7.0 \%$ or $\leq 6.5 \%$ at 6 months as well as the change in body weight between baseline and 6 months. Additionally, we investigated the clinical characteristics of patients who achieved a good response to dulaglutide, which was defined as a decrease in $\mathrm{HbA1c}$ of more than $1.0 \%$ after 6 months of dulaglutide therapy. ${ }^{12}$ We further examined a response to dulaglutide according to the duration of diabetes, BMI, and eGFR.

The self-reported adverse events including hypoglycemia, gastrointestinal problems, and injection-related reactions were collected from a review of the medical records.

\section{Statistical analysis}

Continuous variables were expressed as the mean \pm standard deviation and categorical variables were expressed as the number (\%). The chi-square test was used for the comparison of categorical variables. The paired $t$-test was used to compare the changes in HbA1c and body weight between baseline and 6 months in each treatment group. Intergroup comparisons were undertaken with the analysis of covariance after adjusting for the baseline levels. The changes in each parameter were expressed as the adjusted least square (LS) means and standard error. Univariate and multivariate logistic regression analyses were conducted to evaluate the predictive factors for the therapeutic response to dulaglutide. Risk was reported as odds ratios and $95 \%$ confidence intervals (CIs). All statistical analyses were performed using SPSS software version 25.0 for Windows (IBM Corp., Armonk, NY, USA). p-values $<0.05$ were considered to indicate statistical significance.

\section{RESULTS}

\section{Baseline characteristics of the study population}

The baseline characteristics of the study participants are presented in Table 1 . The mean age was 59.7 years and $35.7 \%$ of them were female. The mean body weight was 77.9 $\mathrm{kg}$ and BMI was $27.7 \mathrm{~kg} / \mathrm{m}^{2}$. The mean duration of diabetes was 12.2 years in the entire study cohort and was significantly longer in the basal insulin combination group than in the OAD combination group $(p=0.015)$. Before the 
TABLE 1. Baseline characteristics of study population

\begin{tabular}{|c|c|c|c|c|}
\hline & $\begin{array}{l}\text { Overall } \\
(\mathrm{n}=112)\end{array}$ & $\begin{array}{l}\text { OAD combination } \\
\qquad(\mathrm{n}=72)\end{array}$ & $\begin{array}{c}\text { Basal insulin } \\
\text { combination }(n=40)\end{array}$ & $\mathrm{p}$ value \\
\hline Age, yr & $59.7 \pm 11.6$ & $58.7 \pm 11.9$ & $61.3 \pm 10.9$ & 0.259 \\
\hline Female sex & $40(35.7)$ & $26(36.1)$ & $14(35.0)$ & 0.906 \\
\hline Height, cm & $166.5 \pm 8.1$ & $166.9 \pm 8.3$ & $165.8 \pm 7.8$ & 0.513 \\
\hline Body weight, kg & $77.9 \pm 16.0$ & $79.3 \pm 17.5$ & $75.3 \pm 12.6$ & 0.225 \\
\hline Body mass index, $\mathrm{kg} / \mathrm{m}^{2}$ & $27.7 \pm 4.2$ & $27.9 \pm 4.3$ & $27.2 \pm 4.1$ & 0.416 \\
\hline Duration of diabetes, yr & $12.2 \pm 8.6$ & $10.7 \pm 7.9$ & $14.9 \pm 9.3$ & 0.015 \\
\hline Systolic blood pressure, $\mathrm{mmHg}$ & $129.2 \pm 15.0$ & $129.9 \pm 15.7$ & $128.1 \pm 13.7$ & 0.552 \\
\hline Diastolic blood pressure, $\mathrm{mmHg}$ & $74.9 \pm 10.8$ & $76.6 \pm 10.6$ & $71.8 \pm 10.7$ & 0.024 \\
\hline $\mathrm{HbA} 1 \mathrm{c}, \%$ & $8.7 \pm 1.4$ & $8.8 \pm 1.5$ & $8.5 \pm 1.4$ & 0.376 \\
\hline Fasting plasma glucose, mg/dL & $180.1 \pm 67.0$ & $190.1 \pm 70.6$ & $159.9 \pm 54.8$ & 0.037 \\
\hline Total cholesterol, mg/dL & $155.7 \pm 43.3$ & $160.0 \pm 37.0$ & $147.7 \pm 52.7$ & 0.175 \\
\hline Triglyceride, mg/dL & $154.7 \pm 92.8$ & $150.1 \pm 87.0$ & $163.8 \pm 103.9$ & 0.486 \\
\hline HDL cholesterol, mg/dL & $43.0 \pm 9.1$ & $42.9 \pm 8.7$ & $43.4 \pm 10.0$ & 0.807 \\
\hline LDL cholesterol, mg/dL & $86.6 \pm 30.4$ & $89.9 \pm 27.1$ & $80.1 \pm 35.4$ & 0.128 \\
\hline Aspartate aminotransferase, U/L & $30.2 \pm 18.6$ & $32.9 \pm 21.5$ & $24.9 \pm 9.5$ & 0.034 \\
\hline Alanine aminotransferase, U/L & $34.2 \pm 26.0$ & $38.5 \pm 30.3$ & $25.8 \pm 10.9$ & 0.012 \\
\hline Serum creatinine, $\mathrm{mg} / \mathrm{dL}$ & $1.05 \pm 0.91$ & $1.05 \pm 0.76$ & $1.06 \pm 0.42$ & 0.981 \\
\hline Estimated glomerular filtration rate, $\mathrm{mL} / \mathrm{min} / 1.73 \mathrm{~m}^{2}$ & $81.5 \pm 30.3$ & $83.8 \pm 30.0$ & $77.2 \pm 31.0$ & 0.400 \\
\hline Hypertension & $65(58.0)$ & $38(52.8)$ & $27(67.5)$ & 0.130 \\
\hline Dyslipidemia & $82(73.2)$ & $51(70.8)$ & $31(77.5)$ & 0.445 \\
\hline Cardiovascular disease & $22(19.6)$ & $15(20.8)$ & $7(17.5)$ & 0.671 \\
\hline Dulaglutide dose & & & & 0.001 \\
\hline $0.75 \mathrm{mg}$ & $29(25.9)$ & $11(15.3)$ & $18(45.0)$ & \\
\hline $1.5 \mathrm{mg}$ & $83(74.1)$ & $61(84.7)$ & $22(55.0)$ & \\
\hline \multicolumn{5}{|l|}{ Treatment before dulaglutide initiation } \\
\hline Insulin therapy & $52(46.4)$ & $12(16.7)$ & $40(100.0)$ & $<0.001$ \\
\hline Daily insulin dose, IU/day & $44.7 \pm 29.7$ & $20.9 \pm 10.1$ & $51.8 \pm 30.0$ & 0.001 \\
\hline \multicolumn{5}{|l|}{$\mathrm{OAD}$} \\
\hline Metformin & $104(92.9)$ & $67(93.1)$ & $37(92.5)$ & 0.913 \\
\hline Sulfonylurea & $66(58.9)$ & $47(65.3)$ & $19(47.5)$ & 0.067 \\
\hline DPP4 inhibitor & $73(65.2)$ & $49(68.1)$ & $24(60.0)$ & 0.391 \\
\hline Thiazolidinedione & $13(11.6)$ & $10(13.9)$ & $3(7.5)$ & 0.312 \\
\hline SGLT2 inhibitor & $9(8.0)$ & $7(9.7)$ & $2(5.0)$ & 0.378 \\
\hline Alpha-glucosidase inhibitor & $2(1.8)$ & $1(1.4)$ & $1(2.5)$ & 0.671 \\
\hline
\end{tabular}

Values are expressed as mean \pm standard deviation or number $(\%)$.

Hypertension is defined as a systolic blood pressure $\geq 140 \mathrm{mmHg}$, or diastolic blood pressure $\geq 90 \mathrm{mmHg}$, or taking anti-hypertensive medication. Dyslipidemia is defined as taking lipid-lowering agents including statin, ezetimibe, fibrate, and omega-3.

OAD: oral anti-diabetic drug, HDL: high-density lipoprotein, LDL: low-density lipoprotein, DPP4: Dipeptidyl peptidase-4, SGLT2: sodium-glucose cotransporter-2.

initiation of dulaglutide therapy, the majority of patients had received metformin. Approximately $46.4 \%$ of the patients were treated with insulin before the initiation of dulaglutide therapy, and the mean total daily insulin dose was 44.7 IU. At the initiation of dulaglutide therapy, approximately $20.9 \mathrm{IU}$ of insulin switched to dulaglutide in the OAD combination group. The mean total daily insulin dose was 51.8 IU in the basal insulin combination group. Six patients titrated their insulin doses ( $>10 \%$ of the baseline) at the initiation of dulaglutide.

At baseline, the mean HbA1c was $8.7 \%$ in all patients, $8.8 \%$ in the $\mathrm{OAD}$ combination group and $8.5 \%$ in the basal insulin combination group. The mean FPG concentration was higher in the $\mathrm{OAD}$ combination group than that in the basal insulin combination group (190.1 mg/dL vs. $159.9 \mathrm{mg} / \mathrm{dL}$, $\mathrm{p}=0.037$ ). There were no significant differences in the baseline fasting lipid profile, serum creatinine, and estimated glomerular filtration rate (GFR) levels between the two groups. Although the levels of aspartate aminotransferase and alanine aminotransferase were higher in the OAD combination group than in the basal insulin combination group ( $\mathrm{p}=0.034$ and $\mathrm{p}=0.012$, respectively), both parameters were within the reference ranges. The prevalence of hypertension, cardiovascular disease, and dyslipidemia did not differ between the two groups. Approximately $74.1 \%$ of all patients received $1.5 \mathrm{mg}$ dulaglutide; the OAD combination group was associated with higher dose of dulaglutide than the basal insulin combination group $(\mathrm{p}=0.001)$. 


\section{Efficacy}

At 6 months, dulaglutide therapy exhibited a significant reduction in $\mathrm{HbA} 1 \mathrm{c}$ levels of $-1.13 \%$ (95\% CI, -1.38 to $-0.89 ; \mathrm{p}<0.001)$ in all patients. Nineteen patients $(17.0 \%)$ showed worsening of $\mathrm{HbA} 1 \mathrm{c}$ at 6 months after dulaglutide therapy compared with the baseline HbA1c. The mean adjusted $\mathrm{HbA} 1 \mathrm{c}$ decreased by $-1.36 \%(95 \% \mathrm{CI},-1.61$ to -1.10$)$ in the OAD combination group and $-0.74 \%$ (95\% CI, -1.08 to -0.40$)$ in the basal insulin combination group $(\mathrm{p}<0.001$ and $\mathrm{p}=0.001$, respectively). The difference in the LS mean change between the two groups was $-0.62 \%$ (95\% CI, -1.04 to $-0.19 ; \mathrm{p}=0.005$; Fig. $1 \mathrm{~A})$. There was a significant reduction of $-2.9 \mathrm{~kg}$ in the body weight in all patients $(\mathrm{p}<0.001)$, and of $-3.5 \mathrm{~kg}$ in the OAD combination group $(\mathrm{p}<0.001)$; however, a statistically significant difference was not observed in the basal insulin combination group $(-1.8 \mathrm{~kg}$, $\mathrm{p}=0.068$ ) (Fig. 1B).

The proportion of patients who achieved HbA1c $<7.0 \%$ at 6 months was $34.8 \%$ in all patients, $41.7 \%$ in the OAD combination group, and $22.5 \%$ in the basal insulin combination group ( $\mathrm{p}=0.041$ ). Moreover, with the HbA1c $\leq 6.5 \%$ as the glycemic target, $23.2 \%$ of all patients achieved the glycemic target goal (31.9\% in the $\mathrm{OAD}$ combination group and $7.5 \%$ in the basal insulin combination group, $p=0.003$; Fig. 1C).

A
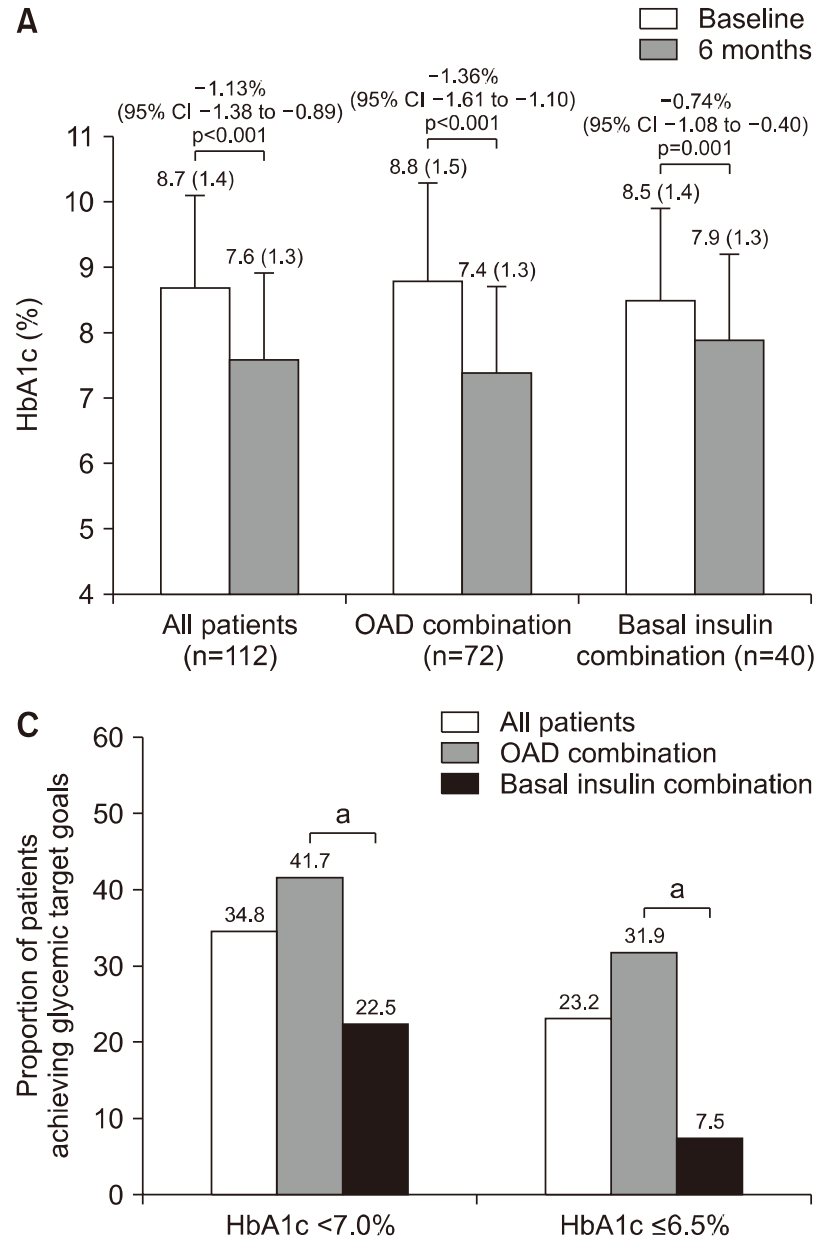

In the $\mathrm{OAD}$ combination group, there was no significant difference in the glucose-lowering efficacy between the insulin-näive and previous insulin therapy group (LS mean change $-1.39 \%$ and $-1.47 \%$, respectively; between-treatment difference in HbA1c of 0.080 [95\% CI, -0.620 to 0.779]; $p=0.821$; Table 2). Similarly, in the basal insulin combination group, the magnitude of the $\mathrm{HbA} 1 \mathrm{c}$ reduction did not differ between the bolus insulin-näive and previous bolus insulin therapy group (LS mean change -0.80 and $-0.68 \%$, respectively; between-treatment difference of -0.217 [95\% CI, -0.930 to 0.497 ]; $\mathrm{p}=0.542$ ). The total daily insulin dose decreased by -20.7 IU in the basal insulin combination group $(\mathrm{p}<0.001)$, and by -16.0 and -23.5 in the bolus insulin-näive and previous bolus insulin therapy group, respectively.

Overall, 60 patients $(53.6 \%)$ were categorized as good responders (HbA1c reduction $\geq 1.0 \%$ ) after 6 months of dulaglutide therapy. Shorter duration of diabetes and higher baseline glycemic parameters (HbA1c and FPG) were associated with a good response to dulaglutide. However, patients who had a history of insulin therapy showed a poor response to dulaglutide (Table 3). Logistic regression analyses were used for the identification of predictable parameters for the glucose-lowering effect of dulaglutide. A univariate regression analysis showed that shorter duration

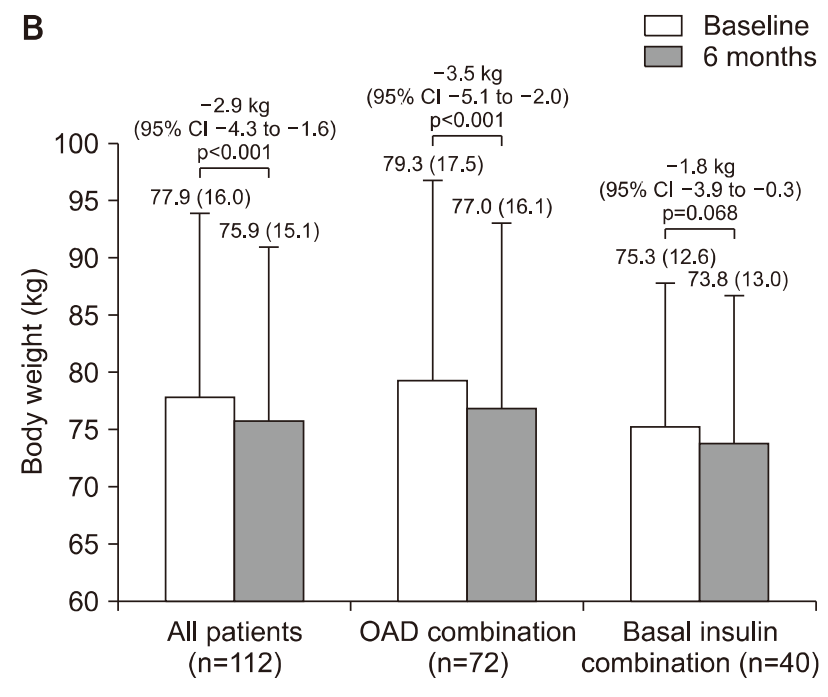

FiG. 1. Changes in (A) HbA1c and (B) body weight between baseline and 6 months of treatment with dulaglutide. (C) Proportion of patients who achieved glycemic target goals of $\mathrm{HbA} 1 \mathrm{c}<7.0 \%$ or $\leq 6.5 \%$. Data are expressed as mean (standard deviation) or $\%$. OAD, oral anti-diabetic drug. ${ }^{\mathrm{a}} \mathrm{p}<0.05$ between $\mathrm{OAD}$ combination and basal insulin combination group. 
TABLE 2. Changes in HbA1c after 6 months of treatment with dulaglutide as OAD combination and basal insulin combination

\begin{tabular}{|c|c|c|c|c|}
\hline Variable & Baseline & 6 months & $\begin{array}{l}\text { LS mean change from } \\
\text { baseline }(95 \% \mathrm{CI})\end{array}$ & $\begin{array}{l}\text { Difference in LS mean } \\
\text { change }(95 \% \text { CI })\end{array}$ \\
\hline \multicolumn{5}{|l|}{ OAD combination } \\
\hline Overall $(\mathrm{n}=72)$ & $8.8 \pm 0.1$ & $7.4 \pm 0.1$ & $-1.36(-1.61 \text { to }-1.10)^{\mathrm{a}}$ & \multirow{3}{*}{$0.080(-0.620$ to 0.779$)$} \\
\hline Insulin-näive $(\mathrm{n}=60)$ & $8.8 \pm 0.2$ & $7.4 \pm 0.2$ & $-1.39(-1.67 \text { to }-1.10)^{\mathrm{a}}$ & \\
\hline Previous insulin therapy $(\mathrm{n}=12)$ & $9.0 \pm 0.5$ & $7.4 \pm 0.4$ & $-1.47(-2.10 \text { to }-0.83)^{\mathrm{a}}$ & \\
\hline \multicolumn{5}{|l|}{ Basal insulin combination } \\
\hline Overall $(\mathrm{n}=40)$ & $8.5 \pm 0.2$ & $7.9 \pm 0.2$ & $-0.74(-1.08 \text { to }-0.40)^{\mathrm{a}}$ & \multirow{3}{*}{$-0.217(-0.930$ to 0.497$)$} \\
\hline Bolus insulin-näive (n=15) & $8.7 \pm 0.3$ & $7.9 \pm 0.4$ & $-0.80(-1.36 \text { to }-0.23)^{\mathrm{a}}$ & \\
\hline Previous bolus insulin therapy $(\mathrm{n}=25)$ & $8.4 \pm 0.3$ & $7.9 \pm 0.3$ & $-0.68(-1.01 \text { to }-0.14)^{\mathrm{a}}$ & \\
\hline
\end{tabular}

Values are presented as mean \pm standard error.

LS: least square, CI: confidence interval. ${ }^{\mathrm{a}} \mathrm{p}<0.05$ from baseline in overall patients and each treatment subgroup.

TABLE 3. Clinical characteristics between the good responder and the poor responders in all patients

\begin{tabular}{|c|c|c|c|}
\hline & Good responders $(\mathrm{n}=60)$ & Poor responders $(\mathrm{n}=52)$ & $\mathrm{p}$ value \\
\hline Age, yr & $58.9 \pm 11.4$ & $60.5 \pm 11.9$ & 0.478 \\
\hline Female sex & $22(36.7)$ & $18(34.6)$ & 0.821 \\
\hline Body weight, kg & $78.6 \pm 17.5$ & $77.0 \pm 14.2$ & 0.590 \\
\hline Body mass index, $\mathrm{kg} / \mathrm{m}^{2}$ & $27.8 \pm 4.3$ & $27.5 \pm 4.2$ & 0.768 \\
\hline Duration of diabetes, yr & $10.2 \pm 8.0$ & $14.6 \pm 8.7$ & 0.008 \\
\hline Hypertension & $39(65.0)$ & $26(50.0)$ & 0.109 \\
\hline Dyslipidemia & $40(66.7)$ & $42(80.8)$ & 0.093 \\
\hline Cardiovascular disease & $12(20.0)$ & $10(19.2)$ & 0.919 \\
\hline Diabetic retinopathy & $16(26.7)$ & $15(28.8)$ & 0.327 \\
\hline Baseline HbA1c, \% & $9.3 \pm 1.3$ & $8.0 \pm 1.3$ & $<0.001$ \\
\hline Baseline fasting plasma glucose, $\mathrm{mg} / \mathrm{dL}$ & $194.4 \pm 65.2$ & $163.1 \pm 65.7$ & 0.022 \\
\hline Previous insulin therapy before dulatlutide initiation & $20(33.3)$ & $32(61.5)$ & 0.003 \\
\hline
\end{tabular}

Values are presented as mean \pm standard deviation or number $(\%)$.

of diabetes, higher baseline $\mathrm{HbA1c}$, and no previous insulin use were associated with a good response to dulaglutide at 6 months. On multivariate analysis, higher baseline $\mathrm{HbA} 1 \mathrm{c}$ and no previous insulin therapy remained statistically significant (Table 4).

We further analyzed the reduction of $\mathrm{HbA} 1 \mathrm{c}$ in all patients according to the duration of diabetes $<10$ years or $\geq$ 10 years, BMI $<25 \mathrm{~kg} / \mathrm{m}^{2}$ or $\geq 25 \mathrm{~kg} / \mathrm{m}^{2}$, and eGFR $<60$ $\mathrm{mL} / \mathrm{min} / 1.73 \mathrm{~m}^{2}$ or $\geq 60 \mathrm{~mL} / \mathrm{min} / 1.73 \mathrm{~m}^{2}$. There were no significant differences in the reduction of $\mathrm{HbA1c}$ with respect to the duration of diabetes, BMI, and eGFR ( $\mathrm{p}=0.177$, $\mathrm{p}=0.158, \mathrm{p}=0.606$, respectively) (Fig. 2).

\section{Safety profiles}

Adverse events were reported in 44 patients (39.3\%) during the 6 months of dulaglutide therapy. The most common adverse events were gastrointestinal problems, including nausea, vomiting, dyspepsia, and abdominal pain (23.2\%). Hypoglycemia was observed in 15 patients (13.4\%), which was associated with the use of sulfonylurea $(n=7)$ and basal insulin ( $n=8)$ as background therapy. Severe hypoglycemia was not reported in the study population during the dulaglutide therapy. Four patients $(3.6 \%)$ had injection-site reactions that were self-limited.
TABLE 4. Logistic regression analysis to predict good responders to dulaglutide in all patients

\begin{tabular}{lcrr}
\hline \multicolumn{1}{c}{ Variable } & Odd ratio & $95 \%$ CI & p value \\
\hline Univariate analysis & & & \\
$\quad$ Age, yr & 0.99 & $0.96-1.02$ & 0.474 \\
Female sex & 0.91 & $0.42-1.99$ & 0.821 \\
Body weight, $\mathrm{kg}$ & 1.01 & $0.98-1.03$ & 0.594 \\
Body mass index, kg/m ${ }^{2}$ & 1.01 & $0.93-1.11$ & 0.766 \\
Duration of diabetes, yr & 0.94 & $0.90-0.99$ & 0.010 \\
Baseline HbA1c, \% & 2.25 & $1.58-3.20$ & $<0.001$ \\
No previous insulin therapy & 3.20 & $1.48-6.94$ & 0.003 \\
Hypertension & 0.54 & $0.25-1.15$ & 0.110 \\
Cardiovascular disease & 0.95 & $0.37-2.43$ & 0.919 \\
Multi-variate analysis & & & \\
$\quad$ Duration of diabetes, yr & 0.96 & $0.90-1.01$ & 0.108 \\
HbA1c, \% & 2.44 & $1.61-3.70$ & $<0.001$ \\
No previous insulin therapy & 4.27 & $1.62-11.3$ & 0.003 \\
\hline
\end{tabular}

CI: confidence interval.

\section{DISCUSSION}

In this analysis of real-world clinical data, we demonstrated that dulaglutide significantly improved the glyce- 


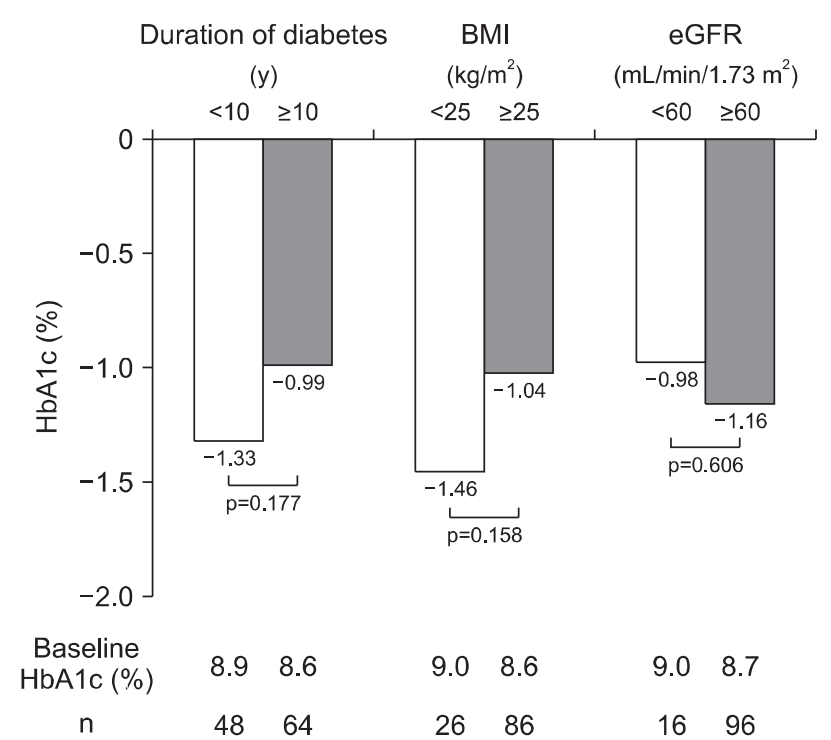

FiG. 2. Changes in HbA1c according to duration of diabetes, body mass index (BMI), and estimated glomerular filtration rate (eGFR) between baseline and 6 months of treatment with dulaglutide.

mic control in Korean patients with T2DM. The glucoselowering efficacy of dulaglutide was observed both in adding to $\mathrm{OAD}$ or adding to basal insulin over a 6 -month period. Moreover, dulaglutide induced significant reduction in body weight. Our findings are similar to those of previous RCTs and real-world clinical studies in patients with T2DM who received dulaglutide treatment.

In the present study, dulaglutide exhibited a significant reduction in $\mathrm{HbA1c}$ of $-1.13 \%$ at 6 months, which was consistent with the results from clinical trials, ${ }^{13-15}$ and similar or slightly greater than that from real-world clinical studies conducted in Western countries. ${ }^{16-18}$ This may be associated with the pharmacokinetic and pharmacodynamic differences of GLP-1 RA in Caucasian and Asians, wherein Asian patients have higher postprandial glucose and postprandial excursion related to impaired $\beta$-cell function. ${ }^{19,20}$ We further analyzed the efficacy of dulaglutide separately as OAD combination or basal insulin because these two regimens are generally accepted in clinical practice. The glucose-lowering efficacy of dulaglutide therapy was observed in both groups. However, the magnitude of $\mathrm{HbA1c}$ reduction was greater in the $\mathrm{OAD}$ combination than in the basal insulin combination group $(-1.36 \%$ vs $-0.74 \%)$. Comparable glycemic efficacy of dulaglutide was reported in previous RCTs with dulaglutide in combination with OADs. The HbA1c-lowering effect of dulaglutide $1.5 \mathrm{mg}$ was $-1.42 \%$ at 26 weeks with metformin in the Assessment of Weekly AdministRation of LY2189265 in Diabetes-6 (AWARD-6) trial and $-1.40 \%$ with sulfonylurea in the AWARD- 8 trial. ${ }^{13,21}$

The observed glucose-lowering efficacy of dulaglutide as a basal insulin combination $(-0.74 \%)$ was lower than those previously reported in the AWARD-9 trial. ${ }^{22}$ In the AWARD-9 trial, the mean HbA1c changes from baseline was $-1.44 \%$ at 28 weeks in T2DM patients after being add- ed to insulin glargine, and $66.7 \%$ of the patients achieved a target goal of HbA1c $<7.0 \%$. Meanwhile, a real-world study in Korean patients revealed a $-0.97 \%$ mean change in $\mathrm{HbA} 1 \mathrm{c}$ at 6 months after dulaglutide therapy as an add-on to basal insulin. ${ }^{11}$ These two studies similarly showed a decrease of $-11.7 \mathrm{IU}$ in the total daily insulin dose, whereas our study showed a decrease of $-20.7 \mathrm{IU}$ at 6 months. This disparity may be attributed to several differences in the study population between the studies as well as real-world factors. In our study, a considerable proportion $(62.5 \%)$ of patients switched the treatment regimen from basal-bolus to basal insulin+dulaglutide in the basal insulin combination group in contrast to the abovementioned studies, and dulaglutide add-on decreased approximately $23.5 \mathrm{IU}$ of insulin. Furthermore, as the insulin dose was self-titrated for the individual patient during dulaglutide treatment, there is a possibility that a marked glucose reduction or hypoglycemia might had led to a subsequently inadequate insulin dose, and the patients' low adherences may have affected the glycemic control.

We analyzed the clinical predictive factors for a good response to dulaglutide. Higher glycemic parameters at baseline and lack of previous insulin therapy were significantly associated with good dulaglutide responses on multivariate regression analysis. A previous pilot study reported that low BMI and old age were linked to good responses to dulaglutide in Japanese patients with T2DM. ${ }^{23}$ A real-world study in Korean patients demonstrated that a higher baseline $\mathrm{HbA1} \mathrm{c}$ was the only predictable factor for good responses to dulaglutide. ${ }^{12}$

Besides the HbA1c change, a significant improvement in body weight $(-2.9 \mathrm{~kg})$ was observed at 6 months after dulaglutide initiation in the overall population. The efficacy of weight reduction in our study was similar to the previous real-world data reported from Western countries, which reported -2.7 to $-2.9 \mathrm{~kg}$ weight reduction at 6 months. ${ }^{16,24}$ Meanwhile, real-world data from Korea showed a weight reduction of $-2.1 \mathrm{~kg}$ during 6 -month dulaglutide therapy in combination with various glucose-lowering treatments, ${ }^{12}$ and $-2.0 \mathrm{~kg}$ at 6 months with dulaglutide as an adjuvant to basal insulin therapy. ${ }^{11}$ These differences may be attributed to the considerable reduction in insulin doses during dulaglutide therapy that leads to a synergic effect on weight loss, as shown in the present study. In addition, several combinations of OADs and selection bias may influence the body weight. In our study, this may have occurred if the patients who stopped dulaglutide earlier due to complaints of no weight change, or took medications that conferred a possibility to gain weight, such as high-dose steroids, were excluded from the analysis.

In the present study, the incidence of gastrointestinal side effects, including mainly nausea, vomiting, and dyspepsia, was similar or slightly higher than those reported in previous RCTs and real-world data. ${ }^{25-28}$ Self-reported hypoglycemia occurred more frequently in our study (13.4\%) than in previous studies and meta-analyses, ${ }^{13,29,30}$ and all of them received sulfonylurea and/or basal insulin. 
Similar to previous studies, all reported cases of hypoglycemia were mild, and no severe hypoglycemia was documented in this study. In this study's cohort, $3.6 \%$ of patients had an injection-site reaction; however, the incidence gradually decreased with repeated injections. Our data supported the safety profiles of dulaglutide in a clinical management plans that were comprised of various glucose-lowering regimens.

There are several limitations in the present study due to its retrospective design. The total cohort sample was small, in particular, for the analysis of glucose-lowering efficacy with regard to the background treatment regimens. Moreover, several parameters, including FPG, lipid profiles, blood pressure, and insulin sensitivity or resistance, were unavailable for an evaluation of the changes after dulaglutide therapy. Furthermore, safety profiles were not collected systematically; therefore, the self-report system might have resulted in over- and under-estimation of adverse events. Nevertheless, this study provided meaningful data on the real-world efficacy of dulaglutide in combination with various background glucose-lowering regimens.

Our findings prove the real-world efficacy and safety profiles of dulaglutide as OAD combination and basal insulin therapy in Korean patients with T2DM. A beneficial effect of body weight reduction was also observed. Dulaglutide therapy could be considered in real-world practice, either as OAD combination or basal insulin therapy in Korean T2DM patients with inadequate glycemic control and/or need for weight reduction.

\section{CONFLICT OF INTEREST STATEMENT}

None declared.

\section{REFERENCES}

1. Kim BY, Won JC, Lee JH, Kim HS, Park JH, Ha KH, et al. Diabetes fact sheets in Korea, 2018: an appraisal of current status. Diabetes Metab J 2019;43:487-94.

2. American Diabetes Association. 9. Pharmacologic approaches to glycemic treatment: Standards of Medical Care in Diabetes-2020. Diabetes Care 2020;43(Suppl 1):S98-110.

3. Davies MJ, D'Alessio DA, Fradkin J, Kernan WN, Mathieu C, Mingrone G, et al. Management of hyperglycemia in type 2 diabetes, 2018. A consensus report by the American Diabetes Association (ADA) and the European Association for the Study of Diabetes (EASD). Diabetes Care 2018;41:2669-701.

4. Umpierrez GE, Blevins T, Rosenstock J, Cheng C, Anderson JH, Bastyr EJ 3rd. The effects of LY2189265, a long-acting glucagon-like peptide-1 analogue, in a randomized, placebo-controlled, double-blind study of overweight/obese patients with type 2 diabetes: the EGO study. Diabetes Obes Metab 2011;13:418-25.

5. Sheahan KH, Wahlberg EA, Gilbert MP. An overview of GLP-1 agonists and recent cardiovascular outcomes trials. Postgrad Med J 2020;96:156-61.

6. Nauck MA, Meier JJ, Cavender MA, Abd El Aziz M, Drucker DJ. Cardiovascular actions and clinical outcomes with glucagon-like peptide-1 receptor agonists and dipeptidyl peptidase-4 inhibitors. Circulation 2017;136:849-70.

7. Tuttle KR, Lakshmanan MC, Rayner B, Zimmermann AG, Woodward B, Botros FT. Body weight and eGFR during dulaglutide treatment in type 2 diabetes and moderate-to-severe chronic kidney disease (AWARD-7). Diabetes Obes Metab 2019;21:14937.

8. Kristensen SL, Rørth R, Jhund PS, Docherty KF, Sattar N, Preiss $\mathrm{D}$, et al. Cardiovascular, mortality, and kidney outcomes with GLP-1 receptor agonists in patients with type 2 diabetes: a systematic review and meta-analysis of cardiovascular outcome trials. Lancet Diabetes Endocrinol 2019;7:776-85.

9. Mody R, Huang Q, Yu M, Patel H, Zhang X, Wang L, et al. Clinical and economic outcomes among injection-naïve patients with type 2 diabetes initiating dulaglutide compared with basal insulin in a US real-world setting: the DISPEL Study. BMJ Open Diabetes Res Care 2019;7:e000884.

10. Ghosh A, Nair R. Improved clinical outcomes with dulaglutide as add-on medication to oral antidiabetic drugs with or without insulin in overweight Indian patients with type 2 diabetes mellitus: retrospective study in a real-world setting. Curr Diabetes Rev 2020;16:490-6.

11. Lee J, Cho YK, Kim HS, Jung CH, Park JY, Lee WJ. Dulaglutide as an add-on to insulin in type 2 diabetes; clinical efficacy and parameters affecting the response in real-world practice. Diabetes Metab Syndr Obes 2019;12:2745-53.

12. Yoo JH, Cho YK, Lee J, Kim HS, Kang YM, Jung CH, et al. Clinical efficacy and parameters affecting the response to dulaglutide treatment in patients with type 2 diabetes: a retrospective, real-world data study. Diabetes Ther 2019;10:1453-63.

13. Dungan KM, Weitgasser R, Perez Manghi F, Pintilei E, Fahrbach JL, Jiang HH, et al. A 24-week study to evaluate the efficacy and safety of once-weekly dulaglutide added on to glimepiride in type 2 diabetes (AWARD-8). Diabetes Obes Metab 2016;18:475-82.

14. Giorgino F, Yu M, Haupt A, Milicevic Z, García-Pérez LE. Effect of once-weekly dulaglutide versus insulin glargine in people with type 2 diabetes and different baseline glycaemic patterns: a post hoc analysis of the AWARD-2 clinical trial. Diabetes Obes Metab 2019;21:2570-5.

15. Kugler AJ, Thiman ML. Efficacy and safety profile of once-weekly dulaglutide in type 2 diabetes: a report on the emerging new data. Diabetes Metab Syndr Obes 2018;11:187-97.

16. Morieri ML, Frison V, Rigato M, D'Ambrosio M, Tadiotto F, Paccagnella A, et al. Effectiveness of dulaglutide in the real world and in special populations of type 2 diabetic patients. J Clin Endocrinol Metab 2020;105:dgaa204.

17. Morieri ML, Rigato M, Frison V, Simioni N, D'Ambrosio M, Tadiotto F, et al. Effectiveness of dulaglutide vs liraglutide and exenatide once-weekly. A real-world study and meta-analysis of observational studies. Metabolism 2020;106:154190.

18. Mody R, Grabner M, Yu M, Turner R, Kwan AYM, York W, et al. Real-world effectiveness, adherence and persistence among patients with type 2 diabetes mellitus initiating dulaglutide treatment. Curr Med Res Opin 2018;34:995-1003.

19. Lu JM. The role of glucagon-like peptide- 1 receptor agonists in type 2 diabetes in Asia. Adv Ther 2019;36:798-805.

20. Yang W, Lu J, Weng J, Jia W, Ji L, Xiao J, et al. Prevalence of dia- 
betes among men and women in China. N Engl J Med 2010;362: 1090-101.

21. Dungan KM, Povedano ST, Forst T, González JG, Atisso C, Sealls $\mathrm{W}$, et al. Once-weekly dulaglutide versus once-daily liraglutide in metformin-treated patients with type 2 diabetes (AWARD-6): a randomised, open-label, phase 3, non-inferiority trial. Lancet 2014;384:1349-57.

22. Pozzilli P, Norwood P, Jódar E, Davies MJ, Ivanyi T, Jiang H, et al. Placebo-controlled, randomized trial of the addition of onceweekly glucagon-like peptide-1 receptor agonist dulaglutide to titrated daily insulin glargine in patients with type 2 diabetes (AWARD-9). Diabetes Obes Metab 2017;19:1024-31.

23. Iwasaki T, Kessoku T, Higurashi T, Taguri M, Yoneda M. Low body mass index and old age are useful in predicting the hemoglobin A1c-lowering effect of switching from sitagliptin to dulaglutide in Japanese patients with type 2 diabetes mellitus: a single-center, open-label, single-arm, pilot study. Diabetol Int 2018; 9:189-95.

24. Unni S, Wittbrodt E, Ma J, Schauerhamer M, Hurd J, RuizNegrón N, et al. Comparative effectiveness of once-weekly glucagon-like peptide-1 receptor agonists with regard to 6-month glycaemic control and weight outcomes in patients with type 2 diabetes. Diabetes Obes Metab 2018;20:468-73.

25. Weinstock RS, Guerci B, Umpierrez G, Nauck MA, Skrivanek Z, Milicevic Z. Safety and efficacy of once-weekly dulaglutide versus sitagliptin after 2 years in metformin-treated patients with type 2 diabetes (AWARD-5): a randomized, phase III study. Diabetes Obes Metab 2015;17:849-58.

26. Moreno Obregón F, Miramontes-González JP, Romo GuajardoFajardo C, Nieto-Sánchez Á, López-Suárez JM, Martín-Vallejo J, et al. Real-life experience with Dulaglutide: analysis of clinical effectiveness to 24 months. Diabetes Res Clin Pract 2019;158: 107916.

27. Li Y, Li L, De Peng Y, Song GY, Ye SD, Du LY, et al. Efficacy and safety of dulaglutide versus insulin glargine in Chinese T2DM patients: a subgroup analysis of a randomized trial (AWARD-CHN2). Diabetes Ther 2019;10:1435-52.

28. Ishii H, Onishi Y, Oura T, Takeuchi M. Once-weekly dulaglutide with insulin therapy for type 2 diabetes: efficacy and safety results from a phase 4 , randomized, placebo-controlled study. Diabetes Ther 2020;11:133-45.

29. Wang J, Li HQ, Xu XH, Kong XC, Sun R, Jing T, et al. The effects of once-weekly dulaglutide and insulin glargine on glucose fluctuation in poorly oral-antidiabetic controlled patients with type 2 diabetes mellitus. Biomed Res Int 2019;2019:2682657.

30. Qie S, Li X, Wang X, Liu Y, Li J, Liu G. Efficacy and safety of long-acting glucagon-like peptide-1 receptor agonist dulaglutide in patients with type 2 diabetes: a systematic review and metaanalysis of 21 randomized controlled trials. Endocrine 2020;68: 508-17. 